\title{
Five tips to aid your health condition
}

\section{Opinion}

Imagine, if you will two patients with the exactly the same injury/ illness.

1. Patient 1 is upbeat, calm, and expecting improvement.

2. Patient 2 is depressed, anxious, and doubtful of any improvement at all.

Which patient do you think will recover faster?

Studies have shown that patients like optimistic Patient 1 above recover faster and more thoroughly than agitated Patient 2 above.

Healing Rate really depends on you as a patient. You have great control over how fast your body heals. Did you know that? Research (see below) has shown that your mind has a great effect on your healing rate.

Healing is defined in the dictionary as to "make free from injury or disease".

1. Wound healing can be measured by progress each day.

2. Healing Rate is somewhat tricky to measure when the illness progress is self-reported, e.g. depression.

Illnesses, like depression, are usually measured in stages of recovery.

Quietly, our minds either speed up or slow down healing. Optimistic thinking is the missing ingredient you might not hear from your doctor, for whatever reason. Worrying and stress hinders healing. Therefore, by shifting your thinking a little, you can choose your healing rate.

Sports realization is where an athlete visualizes defeating the opponent. This concept has not spread too far in the health care area, for reasons that the public might not know.

Now you now know the secret ingredients. What are you going to do about it?

Here are some tips to think healthy, beginning right now.

Think yourself healthy: Imagine how your body is healing, in whatever way you want. You can imagine warriors defeating the illness. You can also imagine an angel or fairy whisking the diseased parts of you away. The choice is up to you.

Sweep unhealthy thoughts away: Worry, stress, and the like are not helping you heal. You could imagine you have a "malware removal system". When worries pop up, the system would automatically usher them out of your mind. How you think is up to you.

Act yourself healthy: Act as if you have the health you desire. Do not act sick. Choose activities that stretch you in a healthy way. Instead of lying there worrying, maybe you could go for a little walk. Do not let your thoughts or other people get you down. Act as if you are healing. Look at your progress each day and tell someone how good you are doing. Watch yourself get better.

\author{
Volume 9 Issue 6 - 2018
}

Tom Garz

Writer and Inventor, TG Ideas LLC, USA

Correspondence: Tom Garz, Writer and Inventor,TG Ideas LLC, USA, Email tgedeas@gmail.com

Received: June 06, 2018 | Published: November 15, 2018

Be with healthy people: Let health rub off on you. Maybe go to the local pool, do some stretches, and listen to the kids play. Let their enthusiasm for life infuse you with health. Turn off the news and shun negative people. They can go their own way. You are busy getting better. Find doctors, friends, and family members that support you in thinking yourself well.

Be grateful for what you do have: Maybe you do not have the health you desire, but there always someone worse off than you are. Look at what you do have and thank the universe for that. Keep building on the good that you do have. Forget about what you do not have. Make the best of what you do have and be happy with that.

Relax: Patients who are relaxed heal quicker and more thoroughly. There are many ways to relax. Find something that appeals to you and that you can do on a consistent basis, especially if you are going to have a long recovery. To measure your relaxation, you could do the following:

a. Use Biofeedback Devices, many of which are available over the counter.

b. If you are hospitalized, watch your Medical Monitor as you relax. Ask your nurse about relaxation techniques, such as deep breathing, and see the results on the Medical Monitor. Your heart rate and blood pressure should decrease as you relax more and more.

c. Another way to measure your relaxation is to monitor your symptoms as you relax, e.g. pain. Your pain is going to be more when you are stressed, so relax as much as possible. Ask your healthcare provider to show you relaxation techniques, especially as it relates to your condition. If your symptoms decrease, especially pain, your doctor might be able to decrease your medications.

d. Of course, work with a healthcare professional with your particular health condition, if you can. Ask your doctor to coach you in thinking yourself well. You have a right to be as healthy and happy as you can be! $!^{1-11}$

\section{Acknowledgements}

None.

\section{Conflict of interest}

The author declares that there is no conflict of interest. 


\section{References}

1. Healing Defined.

2. Cukjati D, Rebersek S, Miklavcic D. A reliable method of determining wound healing rate. Med Biol Eng Comput. 2001;39(2):263-271.

3. Silva H, Larach V. Treatment and recovery rate in depression: a critical analysis. World J Biol Psychiatry. 2000;1(2):119-123.

4. Gouin JP, Kiecolt-Glaser JK. The Impact of Psychological Stress on Wound Healing: Methods and Mechanisms. Immunol Allergy Clin North Am. 2011;31(3):81-93.

5. Walburn J, Weinman J, Norton. Stress, Illness Perceptions, Behaviors, and Healing in Venous Leg Ulcers: Findings From a Prospective Observational Study. Psychosom Med. 2017;79(5):585-592.
6. Robert Ader. was an American psychologist and academic who cofounded psychoneuroimmunology, a field of study which explores the links connecting the brain, behavior, and the immune system.

7. Psychoneuroimmunology.

8. Mind-Body Connection.

9. Sports Visualization.

10. Relaxation Techniques for Health. 2016.

11. Dunford E, DClinPsy MT. Relaxation and Mindfulness in Pain: A Review. Rev Pain. 2010;4(1):18-42. 